DOI 10.37882/2223-2982.2020.07-2.19

\title{
НЕКОТОРЫЕ ПРИЕМЫ ОПТИМИЗАЦИОННОЙ МЕТОДИКИ ОБУЧЕНИЯ ЧТЕНИЮ НА ИНОСТРАННОМ ЯЗЫКЕ СТУДЕНТОВ-НЕЛИНГВИСТОВ
}

\section{SOME WAYS OF THE OPTIMIZATION METHOD SYSTEM OF TEACHING THE NON-LINGUIST STUDENTS TO READ TEXTS IN FOREIGN LANGUAGES}

\section{R. Managarov}

Summary: The purpose of the article is to consider ways of the optimization method system of teaching the non-linguist students to read texts in foreign languages. The quality of teaching needs to be improved. Accordingly, the quality of teaching process can be improved by means of the optimization method system. Special attention in the article is paid to examples of working with some texts.

Keywords: optimization method system; non-linguist students; nonlinguistic institutes; ways of teaching; optimization of teaching; foreign language; reading.
$\mathrm{M}$ етодика обучения иностранным языкам и культурам, как известно, никогда не стоит на месте. Постоянное и непрерывное развитие методической науки обусловлено неисчерпаемым богатством мысли учителей-предметников, педагогов-новаторов, ученых-теоретиков. Благодаря этим исследователям, теория обучения иностранным языкам регулярно пополняется новыми, интересными и актуальными в конкретный исторический период развития данными, фактами, подходами и обогащается креативными приемами, способами и средствами.

Интересен подход, выдвинутый Н.В. Барышниковым о плюрализации обучения языков и культур в современных условиях образования, о полипарадигмальности методических исследований [1,2].

В то же время следует учитывать тот факт, что некая единая концепция обучения все-таки необходима. Речь, разумеется, не идет о жесткой регламентации деятельности педагога в рамках «единственно верной» концепции, теории и подхода. Смысл идеи в том, чтобы в условиях полинаправленности или мультинаправленности современной лингводидактики сфокусироваться на конкретных, актуальных и целесообразных обучающих действиях, методах, подходах и приемах, которые позволят учителю действовать, то есть обучать детей интересно, познавательно, с пользой для жизни.

\author{
Манагаров Роман Викторович \\ К.п.н., дочент, ГБОУ ВО «Ставропольский \\ государственный \\ педагогический институт» филиал в г. Буденновске \\ managarov.roman@yandex.ru
}

Аннотация: Целью данной статьи является исследование приемов оптимизационной методики обучения чтению студентов-нелингвистов на иностранном языке. Качество обучения иностранным языкам в вузах нелингвистического профиля нуждается в улучшении. Повысить качество целесообразно посредством оптимизации методики обучения в неязыковом вузе. Основное внимание в статье уделяется примерам работы с текстами на немецком языке.

Ключевые слова: оптимизационная методика; студенты-нелингвисты; нелингвистический вуз; приемы обучения; оптимизация обучения; иностранный язык; чтение.

В данной связи мы говорим об оптимизации методики обучения в целом и об оптимизации методики обучения видам речевой деятельности, в частности. «Оптимизировать» в Толковом словаре русского языка С.И. Ожегова и Н.Ю. Шведовой означает «придать чему-нибудь оптимальные свойства, показатели; выбирать наилучший из возможных вариантов» [5:с.448]. Перекладывая смысл на теорию обучения иностранным языкам и культурам, отметим, что оптимизация предполагает некое улучшение, усовершенствование и, в то же время, упрощение обучения с целью повышения качества образовательного процесса.

О том, что качество обученности студентов-нелингвистов в области иностранных языков, далеко не идеально, известно, как мы полагаем, давно. Существуют различные пособия, учебники, монографии, диссертации и пр. литература относительно исследований данной проблемы. Многие исследования действительно заслуживают внимания и являются практико-применимыми. В то же время, преподаватели-практики нуждаются в методических пособиях, иных учебных материалах, помогающих ориентироваться в этом «плюрализме» мнений современной теории обучения иностранным языкам. В таких пособиях, которые будут предлагать конкретные способы организации учебного материала, содержать актуальные задания и упражнения по конкретной теме, учитывая факторы когнитивности, коммуникативности, 
креативности [3: с. 4].

Особенно данная работа актуальна в области обучения иностранным языкам студентов вузов нелингвистического профиля. Практика показывает, что предмет «Иностранный язык» для большинства студентов таких вузов не интересен, отношение к нему как к предмету «для галочки», второстепенному и подчас скучному, и не нужному. Такое негативное отношение формируется не на пустом месте. Разумеется, что и мы преподаватели в каком-то смысле прикладываем руку к этому. Ситуация требует изменений. Занятия по иностранному языку лимитированы, времени, отводимого на овладение иноязычной коммуникативной компетенцией, мало, поэтому занятия необходимо переформатировать: трансформировать теоретико-грамматический подход в практикоориентированный. Осуществлять это необходимо в соответствии с повышением требований к ФГОС к уровню владения иностранным языком обучающимися всех типов учебных заведений [4: с.152]. В этом, как нам видится, и есть суть оптимизации современной методики.

Оптимизация в данной связи основывается на актуальных методах и подходах (коммуникативном, когнитивном, социокультурном, деятельностном и др.), но, в то же время, предполагает учет таких факторов, как отсутствие заинтересованности некоторых современных студентов в получении знаний, в прикладывании усилий для достижения положительного результата, неумении работать с книгой, словарем, отсутствие удовлетворенности от проведения исследовательской работы, рассеянности внимания и пр.

Следовательно, оптимизационная методика должна предложить такую модель обучения, которая будет способствовать повышению качества обучения в целом и конкретным видам речевой деятельности в частности.

В конкретном случае мы говорим об обучении чтению студентов вузов неязыкового профиля. Умение читать - одно из наиболее существенных умений, как представляется, если рассматривать неязыковой вуз. Зачастую практикум по чтению превращается в долгий и скучный процесс перевода со словарем, поиска ответов на вопросы. Такая деятельность для плохо владеющих иностранным языком студентов не интересна и не продуктивна в практическом смысле.

Рассмотрим некоторые приемы оптимизации методики обучения чтению в неязыковом вузе на материале следующих специально разработанных текстов для начинающих изучать иностранный язык.

Студентам предлагаются для ознакомления следующие тексты на немецком языке:

Maja ist 21. Sie kommt aus Berlin. Sie ist Studentin. Maja studiert Medizin an Berliner Universität. Sie hat eine Familie: eine Mutter, einen Vater, einen Bruder und einen Hund. Majas Vater ist Ingenieur. Majas Mutter ist Ärztin. Majas Bruder Klaus lernt noch in der Schule. Und Majas Hund heißt «Kook». Er ist sehr lustig und klug. Maja hat ein Hobby. Sie bastelt gerne. Sie hat einen Freund Rascheed, sie studieren zusammen und er mag auch basteln.

Niko ist 27. Er kommt aus Tirana. Aber jetzt wohnt er in Amsterdam. Er arbeitet als Autofahrer. Er mag seine Arbeit. Niko hat eine große Familie. Sie treffen sich sehr oft, besonders wenn man albanische Nationalfeste feiert. Niko hat eine Frau. Sie heißt Luisa. Sie kommt aus Surinam. Sie ist 22. Sie arbeitet als Krankenschwester. Niko hat kein Hobby. Er arbeitet viel, es gibt keine Zeit für ein Hobby.

Lena ist 31. Sie ist Verkäuferin. Sie kommt aus Dnepr. Sie wohnt jetzt in Ontario. Sie ist verheiratet, ihr Mann ist Kanadier. Er arbeitet als Fußballmanager. Lenas Eltern wohnen in der Ukraine. Sie hat eine Mutter, einen Vater und eine Oma. Lena besucht ihre Familie im Sommer. Sie hat auch ein Hobby. Sie kocht gerne. Lena ist eine Fußballfreundin. Sie mag selbst Fußball spielen.

Tomasz kommt aus Polen, er ist 25. Er wohnt aber in Hamburg. Er arbeitet als Kellner. Er hat viele Freunde. Sie treffen sich oft und verbringen ihre Freizeit sehr lustig. Die Eltern von Tomasz wohnen auch in Deutschland, aber nicht in Hamburg. Er besucht sie, wenn er Freizeit hat. Tomaszs Hobby ist Singen. Er mag Hip-Hop und rappt manchmal im Klub. Er spielt auch gerne Hockey.

Raheem ist Student, er kommt aus Jamaika. Er studiert Chemie in Frankreich. Raheem ist 22. Er ist Sportler. Er spielt Basketball und Fußball. Sport ist auch sein Hobby außer Studium. Raheem hat viele Freunde. Sie sind auch Studenten aus Mali, Senegal, Kroatien, Ungarn und sogar Peru. Raheem hat eine Mutter. Er liebt sie und unterstützt sie. Raheems Mutter wohnt in Jamaika.

Malika kommt aus Tunesien. Sie ist 28. Sie wohnt mit ihrer Familie in Deutschland, in Leipzig. Malikas Vater ist Professor. Er arbeitet an der Uni. Malikas Mutter ist Hausfrau. Sie hat auch 3 Brüder. Sie sind noch klein. Malika ist Sekretärin und Dolmetscherin. Sie ist verheiratet, ihr Mann heißt Samir. Er arbeitet mit Malika als Manager einer Privatfirma für Business und Übersetzen. Malika hat eine Tochter. Sie heißt Stella.

Peter ist 24. Er ist Fußballfan von Borussia Dortmund. Fußball ist sein Hobby. Er arbeitet als Elektriker. Peter hat eine Freundin, sie heißt Sonja und einen Freund Hans. Sie sind auch Fußballfans. Sie besuchen immer Fußballspiele von Borussia und unterstützen die Liebliengsmannschaft.

Заметим, что данные тексты не переводятся дословно и не «вычитываются». На основании беглого просмо- 
трового чтения, мы предлагаем следующие задания:

1. Выберите правильный вариант перевода слова. Студенты просматривают, читают тексты про себя. Затем, ориентируясь на текст, находят нужное слово и озвучивают его. Можно работать в группе, индивидуально, парно, в формате викторины.

Текст 1: мастерить; университет; собака; изучать; семья; брат; веселый и умный; хобби; друг; студентка; инженер.

Текст 2: жить; медсестра; албанские национальные праздники; встречаться; жена; работать; хобби; работа.

Текст 3: играть в футбол; готовить; продавщица; футбольный тренер; родители; бабушка; любительницы футбола.

Текст 4: официант; проводить свободное время; родители Томаша; посещать, навещать; пение; читать рэп; играть в хоккей.

Текст 5: химия; играть в баскетбол; студент; мама; поддерживать; проживать.

Текст 6: работать в университете; домохозяйка; маленький; переводчица; менеджер; дочь; ее зовут.

Текст 7: футбольный фанат; электрик; подруга; футбольные игры; поддерживать.

2. Студенты просматривают тексты в течение определенного короткого отрезка времени. Затем им следует закрыть тексты и, слушая утверждение, определить, к какому персонажу относится то или иное утверждение. Можно работать в группе, индивидуально, парно, в формате викторины:

Er arbeitet als Autofahrer.

Sie hat eine Tochter, die Stella heißt.

Ihr Mann arbeitet als Fußballmanager.

Sie bastelt gerne.

Seine Mutter wohnt in Jamaika.

Er mag Hockey.

Seine Freundin heißt Sonja.

Sie besucht ihre Familie im Sommer.

Ihr Mann arbeitet mit ihr in einer Firma.

Er spielt Basketball und Fußball.

Seine Frau heißt Luisa.

Er ist Elektriker.
Seine Eltern wohnen nicht in Hamburg, aber in Deutschland.

Sie hat einen Freund Rascheed.

Er hat zwei Freunde, die Fußballfans sind.

Ihr Vater arbeitet an der Uni.

Er hat viele Freunde, die Studenten sind.

Er rappt mit seinen Freunden.

Kochen ist ihr Hobby.

Er hat keine Zeit für ein Hobby.

Ihr Hund heißt Kook.

3. Студенты снова просматривают в течение нескольких минут данные тексты и выполняют задания «правильно/не правильно следующее утверждение». Можно работать в группе, индивидуально, парно, в формате викторины.

Maja kommt aus Tunesien. Niko wohnt in Amsterdam. Lena ist 31. Tomasz wohnt in Bonn. Raheem studiert Pädagogik in Wien. Malika ist 28. Peter ist Fußballfan von Bayern. Maja ist Verkäuferin. Niko hat eine große Familie. Lena wohnt mit ihrem Mann in Toronto. Tomasz arbeitet als Manager. Raheems Hobby ist Sport. Malika hat eine Schwester. Peters Freundin heißt Sanja. Majas Hobby ist wandern. Peter ist Elektriker von Beruf. Raheem hat eine Mutter, die in Jamaika wohnt. Malika ist noch nicht verheiratet. Tomasz mag Sport. Lena mag Fußball spielen. Niko kommt aus Surinam.

4. Угадай людей по фото. Преподаватель предлагает изображения указанных в тексте персонажей, а студенты ассоциируют фото с действующим лицом конкретного текста.

5. Подбери слова к тексту. Студенту необходимо по предложенным словам определить, к какому тексту они относятся (о ком идет речь): Medizin; Borussia Dortmund; Sekretärin; Jamaika; Hamburg; kochen; Autofahrer; Kook; Elektriker; 28 Jahre alt; Sonja und Hans; Stella; 22 Jahre alt; Singen; Fußballmanager; Tirana; Klaus; Privatfirma für Business und Übersetzen; Chemie; Kellner; Ontario; Luisa; basteln; Krankenschwester.

6. Составь краткую характеристику каждого (отдельного) персонажа в письменной или устной форме.

\section{ЛИТЕРАТУРА}

1. Барышников Н.В. Плюралистическая дидактика языков и культур. Лингводидактические проблемы формирования иноязычных компетенций // Коллективная монография по материалам международного научно-методического симпозиума «Лемпертовские чтения XIX». 2017 - C. 16 - 22.

2. Барышников Н.В. Обучение иностранным языкам и культурам: методология, цель, метод // Иностранные языки в школе. - $2014-$ № 9 - С. 2 - 9.

3. Манагаров Р.В. Педагогическое мастерство (преподавателя новой формации): учебно-методическое пособие. Чехов: ЦОИНК, 2020. - 57 с.

4. Манагаров Р.В., Красножонова Е.С. Рационализация процесса подготовки будущего учителя иностранного языка и культуры новой формации // Современные исследования социальных проблем (электронный научный журнал). Красноярск, 2016. №3-2 - С. 151-158.

5. Ожегов С.И., Шведова Н.Ю. Толковый словарь русского языка // Российская АН; Российский фонд культуры; - 2-е изд.,испр. и доп. - М. АЗъ, 1995. - 928 с.

(c) Манагаров Роман Викторович (managarov.roman@yandex.ru)

Журнал «Современная наука: актуальные проблемы теории и практики» 